\title{
Effects of nitrogen supply methods on fate of nitrogen in maize under alternate partial root-zone irrigation
}

\author{
Dongliang $\mathrm{Qi}^{1}$, Tiantian $\mathrm{Hu}^{2 *}$, Xue Song ${ }^{2}$ \\ (1. Engineering Research Center of Ecology and Agriculture Use of Wetland, Ministry of Education, Yangtze University, \\ Jingzhou 434025, Hubei, China; \\ 2. Key Laboratory of Agricultural Soil and Water Engineering in Arid and Semiarid Areas of Ministry of Education, \\ Northwest A\&F University, Yangling 712100, Shaanxi, China)
}

\begin{abstract}
Partial root-zone irrigation (PRI) has been practiced worldwide, but little information is available on nitrogen (N) supply methods influence on fate of applied $\mathrm{N}$ fertilizer for crop production under PRI. A field experiment was conducted to investigate effect of $\mathrm{N}$ supply methods on the uptake, residual, and loss of applied $\mathrm{N}$ fertilizer in maize (Zea mays L.) under alternate PRI at Wuwei, northwest China in $2014 .{ }^{15} \mathrm{~N}$-labeled urea was used as $\mathrm{N}$ fertilizer. Two irrigation methods included alternate furrow irrigation (AI) and conventional furrow irrigation (CI). Two N fertilizer supply methods included conventional $\mathrm{N}$ supply (CN) and alternate $\mathrm{N}$ supply (AN), were applied in combination with each irrigation method. Grain yield, root length density (RLD), $\mathrm{N}$ uptake by maize at the maturity stage, and atom $\%$ of ${ }^{15} \mathrm{~N}$ excess, residual ${ }^{15} \mathrm{~N}$ and residual $\mathrm{NO}_{3}-\mathrm{N}$ in the 0-100 cm soil layer after maize harvest were determined. Results shown that compared to CI coupled with CN, AI coupled with AN or CN significantly increased the grain yield, harvest index, RLD, $\mathrm{N}$ uptake by maize, ${ }^{15} \mathrm{~N}$ accumulation in grain, atom $\%$ of ${ }^{15} \mathrm{~N}$ excess in the 0-60 cm soil layer, the residual ${ }^{15} \mathrm{~N}$ and ${ }^{15} \mathrm{~N}$ uptake rates; but significantly decreased the residual $\mathrm{NO}_{3}-\mathrm{N}$ in the $0-100 \mathrm{~cm}$ soil layers and ${ }^{15} \mathrm{~N}$ loss rate. Moreover, the synchronized rather than separation supply of $\mathrm{N}$ fertilizer and water enhanced the most above parameters under AI. ${ }^{15} \mathrm{~N}$ uptake rate was positively correlated with RLD in the 0-40 cm soil layer, suggesting that the enhanced RLD contributed to the improved ${ }^{15} \mathrm{~N}$ uptake rate. Therefore, alternate furrow irrigation coupled with conventional or alternate nitrogen supply (synchronized supply of $\mathrm{N}$ fertilizer and water) could help improve ${ }^{15} \mathrm{~N}$ uptake rate and reduce the ${ }^{15} \mathrm{~N}$ loss rate.
\end{abstract}

Keywords: ${ }^{15} \mathrm{~N}$-labeled technology, root length density, nitrogen fertilizer fate, nitrogen management, residual nitrogen DOI: $10.25165 /$ j.ijabe.20201303.5287

Citation: Qi D L, Hu T T, Song X. Effects of nitrogen supply methods on fate of nitrogen in maize under alternate partial root-zone irrigation. Int J Agric \& Biol Eng, 2020; 13(3): 129-135.

\section{Introduction}

The increasing freshwater consumption has encouraged more research into developing novel irrigation strategies to improve crop water use efficiency (WUE) ${ }^{[1]}$. Partial root-zone irrigation (PRI) and deficit irrigation (DI) are water-saving irrigation techniques which have been intensively studied in many regions of the world. In DI, the entire root zone is irrigated with an amount of water less than that of potential evapotranspiration, which could induce minor stress with minimal effects on yield ${ }^{[2]}$. PRI is a further refinement of DI. In PRI, half of the root zone is irrigated, while the other half is left dry ${ }^{[3]}$. There are two ways for PRI application, namely alternate PRI (APRI) and fixed PRI (FPRI). It has been shown that PRI can allow the induction of the abscisic acid-based root-to-shoot chemical signaling to regulate growth and water use $\mathrm{e}^{[4]}$. Moreover, given a same amount of irrigation water, APRI was superior to DI and FPRI in terms of yield maintenance and increase

Received date: 2019-07-14 Accepted date: 2020-04-20

Biographies: Dongliang Qi, PhD, Lecturer, research interests: regulation of agricultural soil and water environment, Email: qd1198799@126.com; Xue Song, Master, Engineer, research interests: technology of water-saving irrigation, Email: 1296085794@qq.com;

*Corresponding author: Tiantian Hu, PhD, Professor, research interests: high efficient use of water and fertilizer resources. Key Laboratory of Agricultural Soil and Water Engineering in Arid and Semiarid Areas of Ministry of Education, Northwest A\&F University, Yangling 712100, China. Tel: +86-29-87082901, Email: hutiant@nwsuaf.edu.cn. in $\mathrm{WUE}^{[5-9]}$. In addition, nitrogen $(\mathrm{N})$ is another essential resource for crop production. And, $\mathrm{N}$ fertilizer is one of the most energy-consuming chemical products and is expensive, owing to the growing global demand for fossil fuels. Also, the extensive and non-agronomic based application of $\mathrm{N}$ fertilizer has reduced $\mathrm{N}$ use efficiency (NUE) and caused numerous environmental issues $^{[10]}$. Therefore, the sustainable use of water and $\mathrm{N}$ fertilizer has become a priority for agriculture, especially in water deficit regions.

Apart from supply level of $\mathrm{N}$ fertilizer and amount of irrigation water, supply patterns of water and $\mathrm{N}$ fertilizer play a vital role in determining WUE, NUE and the distribution of residual soil $\mathrm{NO}_{3}-\mathrm{N}$. In comparison with conventional furrow irrigation (CI) and fertilization, the separation of $\mathrm{N}$ fertilizer and water with APRI increased WUE by 13\%-33\%, agronomic efficiency of $\mathrm{N}$ fertilizer by $36 \%-56 \%$, and $\mathrm{NO}_{3}-\mathrm{N}$ in the upper soil layers $(0-60 \mathrm{~cm})$ by $30 \%-60 \%$ in a semi-arid area ${ }^{[11]}$. Placement of $\mathrm{N}$ fertilizer in non-irrigated rather than irrigated furrow could improve the $\mathrm{N}$ uptake as well as reduce the possibility of $\mathrm{NO}_{3}-\mathrm{N}$ leaching under FPRI in a relatively wet season ${ }^{[12]}$. However, $\mathrm{N}$ fertilizer accumulation in the plant was reduced by $50 \%$ when it was placed in the no-irrigated furrow under FPRI in a drier year ${ }^{[13]}$. Thus, effect of $\mathrm{N}$ fertilizer supply patterns on $\mathrm{N}$ uptake and water utilization in crops are not consistent under PRI, which merits additional study.

$\mathrm{N}$ uptake by crops mainly comes from two sources: namely soil initial $\mathrm{N}$ and applied $\mathrm{N}$ fertilizer. It has been shown that the 
$\mathrm{N}$ uptake by plants and fate of applied $\mathrm{N}$ fertilizer depend largely on climatic factors and agricultural management practices ${ }^{[14]}$. Compared with the conventional irrigation (full irrigation), APRI could enhance the $\mathrm{N}$ accumulation in maize $\mathrm{e}^{[7,15,16]}$, wheat ${ }^{[17]}$ and tomato ${ }^{[18]}$. The recovery rate of ${ }^{15} \mathrm{~N}$ fertilizer was greater in the APRI treatment than that in the CI treatment, and the residual percentage of ${ }^{15} \mathrm{~N}$ fertilizer showed an opposite observation ${ }^{[7]}$. Moreover, the enhanced plant $\mathrm{N}$ nutrition is responsible for the improved WUE under APRI ${ }^{[19]}$. In addition, the Hexi Corridor area is one of the most important food production areas in China, where crop production depends heavily on irrigation due to infrequent precipitation ${ }^{[20]}$. PRI has been widely being practiced in this region in recent years ${ }^{[21,22]}$. Therefore, exploring fate of applied $\mathrm{N}$ fertilizer in crops under PRI is essential for high economic return and environmental protection in this region.

Soil $\mathrm{N}$ and water availability are closely linked and mutually influences one another ${ }^{[23]}$, and the interaction and complementary activities of nutrients and water play an important role in agricultural production $^{[24]}$. Moreover, it has been shown that an appropriate $\mathrm{N}$ supply pattern could help improve $\mathrm{N}$ accumulation in crop plants ${ }^{[25-26]}$. N fertilizer applied to the topsoil was useful to increase the recovery of ${ }^{15} \mathrm{~N}$-labeled nitrate ${ }^{[27]}$. Also, the deep placement of coated urea is an efficient $\mathrm{N}$ supply method to produce a high yield of soybean ${ }^{[26]}$. Furthermore, an earlier study illustrated that traditional $\mathrm{N}$ management leading to substantial losses of $\mathrm{N}$ fertilizer under intermittent irrigation ${ }^{[28]}$. However, in most investigations on PRI, the main pattern of $\mathrm{N}$ supply is uniformly applied either as a basal application or topdressing, in which the coordination of $\mathrm{N}$ supply and irrigation pattern received relatively limited attention ${ }^{[12,29]}$. In addition, our previous work has shown that APRI coupled with conventional or alternate $\mathrm{N}$ supply could improve growth and distribution of maize roots, and maintain more soil $\mathrm{NO}_{3}-\mathrm{N}$ and water within the upper soil layers $(0-40 \mathrm{~cm})$ for a longer period of time as compared with the conventional irrigation and fertilization ${ }^{[30-31]}$. However, whether fate of $\mathrm{N}$ fertilizer is influenced by $\mathrm{N}$ supply patterns under PRI and the mechanisms behind this remains largely unknown.

The objective of this study was to investigate the effect of $\mathrm{N}$ supply patterns on the fate of $\mathrm{N}$ fertilizer in maize under APRI as compared to CI and to elucidate the causes of possible differences. The results should provide a basis for scientific management of irrigation water and $\mathrm{N}$ fertilizer under PRI.

\section{Materials and methods}

\subsection{Experimental site}

A field study was carried out at the Wuwei Experimental Station for Efficient Use of Crop Water, Ministry of Agriculture, northwest China during the 2014 growing season. The site is in a typical continental temperate climate zone with mean annual precipitation of $164.4 \mathrm{~mm}$, mean annual evapotranspiration of $2000 \mathrm{~mm}$. The cumulative average temperature for days with mean temperature above $10^{\circ} \mathrm{C}$ is $3500-4000^{\circ} \mathrm{C}$. The average air temperature, precipitation, and sunshine hours during the maize-growing season of 2014 measured at a weather station within the experimental site are shown in Table 1 . The soil is classified as a clay loam (FAO, 1998). In the plough layer (0$40 \mathrm{~cm}$ soil layer), organic matter $15.90 \mathrm{~g} / \mathrm{kg}$, total N $0.55 \mathrm{~g} / \mathrm{kg}$, total phosphorus $0.93 \mathrm{~g} / \mathrm{kg}$, available phosphorus $6.22 \mathrm{mg} / \mathrm{kg}$ and available potassium $236.24 \mathrm{mg} / \mathrm{kg}$. $\quad \mathrm{NO}_{3}^{-}-\mathrm{N}$ in the $0-100 \mathrm{~cm}$ soil layer was $35 \mathrm{~kg} / \mathrm{hm}^{2}$ and $\mathrm{NH}_{4}{ }^{+}-\mathrm{N}$ was $21 \mathrm{~kg} / \mathrm{hm}^{2}$ before the start of the experiment. The latitude, longitude and groundwater level at the site is described in details by Qi et al. ${ }^{[31]}$.

Table 1 Precipitation, sunshine hours, and mean temperature during growing season of maize in 2014 at experimental site

\begin{tabular}{cccccc}
\hline April & May & June & July & August & September \\
\hline \multicolumn{5}{c}{ Precipitation (mm per month) } \\
\hline 20 & 17 & 12 & 46 & 75 & 5 \\
\hline \multicolumn{5}{c}{ Sunshine (h per month) } \\
\hline \multicolumn{5}{c}{ Mean temperature $\left({ }^{\circ} \mathrm{C}\right)$} \\
\hline 7.6 & 226 & 17.2 & 22.2 & 259 \\
\hline
\end{tabular}

Note: Temperatures are the monthly averages.

\subsection{Crop management and experimental design}

Furrows and ridges established were described in details by Qi et al. $^{[31]}$. Briefly, the main plots measured $4 \mathrm{~m} \times 8 \mathrm{~m}$ each, arranged in a randomized complete block design with three relocates. Ridges were built in a west-east direction. $45 \mathrm{~kg} \mathrm{P}_{2} \mathrm{O}_{5} / \mathrm{hm}^{2}$ (triple superphosphate) was uniformly applied before the planting.

The experiment factors comprised of irrigation method and $\mathrm{N}$ fertilizer supply method. Irrigation methods included conventional furrow irrigation (CI) and alternate furrow irrigation (AI). $\quad \mathrm{N}$ supply methods included conventional $\mathrm{N}$ supply (CN) and alternate $\mathrm{N}$ supply (AN). The definition of AI, CI, AN and $\mathrm{CN}$ and FN are described in details by Qi et al. ${ }^{[31]}$. Briefly, the alternate treatments refer to alternatively supply of $\mathrm{N}$ or water to one certain furrow of neighboring furrows; and the conventional treatments refer to supply of water or $\mathrm{N}$ evenly to all furrows. This experimental plan yielded four treatments, i.e. CIAN, CICN, AIAN and AICN. In addition, AIAN was applied in two ways, namely synchronized supply of $\mathrm{N}$ fertilizer and water under $\mathrm{AI}$ (AIANS) and separation supply of $\mathrm{N}$ fertilizer and water under $\mathrm{AI}$ (AIAND). The ${ }^{15} \mathrm{~N}$ study reported here was carried out in microplots that were nestled within the main plot, and when the main plots received the treatment, these microplots were left unfertilized and no-irrigated.

\subsection{Microplot setup and management}

${ }^{15} \mathrm{~N}$ microplot was $1.5 \mathrm{~m}^{2}(1.5 \mathrm{~m} \times 1 \mathrm{~m})$ and ${ }^{15} \mathrm{~N}$-labeled urea (abundance $10.19 \%$, produced by the Institute of Chemical Industry in Shanghai, China) was applied to the microplots. A zinc-galvanized iron sheet was used to forming a profile of the microplots. The profile was $0.65 \mathrm{~m}$ in depth below the soil surface and $0.55 \mathrm{~m}$ in height above the ground.

Twice as much water and/or $\mathrm{N}$ was applied to the irrigated/fertilized furrow in the alternate treatments as that to the furrow in the conventional treatments, resulted in the same input of $\mathrm{N}$ fertilizer and irrigation water for all treatments. $200 \mathrm{~kg} \mathrm{~N} / \mathrm{hm}^{2}$ $\left({ }^{15} \mathrm{~N}\right.$-labeled urea), a recommended $\mathrm{N}$ rate for maize production in the local area ${ }^{[32]}$, was applied to each microplot. $\mathrm{N}$ fertilizer was applied before planting (50\%), and at the $\mathrm{V}_{12}$ (25\%) and VT (25\%) stages of maize. The corresponding dates were 19 April, 12 July and 1 August in 2014, respectively. According to Ju et al. ${ }^{[14]}$, $10 \mathrm{~cm}$ of the topsoil the in furrows from the microplot was removed, passed through a $5 \mathrm{~mm}$ sieve, mixed with N-labeled urea, and then refilled with this mixture before sowing for the basal application of labeled fertilizer N. Top-dressing of N-labeled urea was sprayed to the center of the furrows and was immediately followed by irrigation. According to Yang et al. ${ }^{[33]}$, the irrigation water was applied after planting and at the $V_{6}, V_{12}$, VT, $R_{1}$ and $R_{4}$ of maize (45 mm per time), respectively. Underground water with electrical conductivity of $0.52 \mathrm{dS} / \mathrm{m}$ was used as the irrigation 
source. A water meter installed at the discharging end of the pipe to measure the amount of the irrigation water. The details of partial irrigation and $\mathrm{N}$ fertilizer application for all treatments are shown in Table 2.

Table 2 Time and position of localized irrigation and nitrogen (N) application to maize grown for different irrigation and nitrogen supply methods

\begin{tabular}{cccccc}
\hline \multirow{2}{*}{$\begin{array}{c}\text { Maize growth } \\
\text { period }\end{array}$} & \multicolumn{4}{c}{ Position of localized irrigation and nitrogen application } \\
\cline { 2 - 3 } & \multicolumn{2}{c}{ Irrigation method } & & Nitrogen supply method \\
\cline { 2 - 3 } \cline { 5 - 6 } Before planting & $/$ & CI & & South furrow & Both furrows \\
After planting & Both furrows & Both furrows & $/$ & / \\
$\mathrm{V}_{6}$ & South/north furrow & Both furrows & $/$ & / \\
$\mathrm{V}_{12}$ & South/north furrow & Both furrows & North furrow & Both furrows \\
$\mathrm{VT}$ & South/north furrow & Both furrows & South furrow & Both furrows \\
$\mathrm{R}_{1}$ & South/north furrow & Both furrows & $/$ & / \\
$\mathrm{R}_{4}$ & South/north furrow & Both furrows & & \\
\hline
\end{tabular}

Note: “/” represents no treatment; AI, alternate furrow irrigation; CI, conventional furrow irrigation; AN, alternate $\mathrm{N}$ supply; $\mathrm{CN}$, conventional $\mathrm{N}$ supply; Irrigation was conducted in north furrow for AIANS treatment, and in south furrow for AIAND and AICN treatments. Abbreviations indicate are same in the below. 100,50 and $50 \mathrm{~kg} \mathrm{~N} / \mathrm{hm}^{2}$ was applied before planting, and at the 12 collars and tasseling stage of maize, respectively. The rate of irrigation and $\mathrm{N}$ application per time was the sum of $\mathrm{N}$ and water supply to the both furrows (south and north furrow).

Grain maize with variety of 'Golden northwest No.22' was sown in the ridges; the planted density was 73000 plants $/ \mathrm{hm}^{2}$. The crop was sown on April 20, and was harvested on September 22 in 2014. Besides, water and $\mathrm{N}$ and the other agronomic managements in the main plots were very similar to those in the microplots excepted for common urea was used as a source of $\mathrm{N}$ fertilizer in the former.

\subsection{Plant and soil sampling and laboratory procedures}

Maize above-ground in the microplots were cut at the $\mathrm{R}_{6}$ and then partitioned into the different organs for the dry matter yield (included grain yield, corrected to $15.5 \%$ of moisture content) and total $\mathrm{N}$ uptake determination. According to Ju et al. ${ }^{[14]}$, the plant material was ground to $<0.15 \mathrm{~mm}$ sieve, and then analyses for total $\mathrm{N}$ by the Kjeldahl method and ${ }^{15} \mathrm{~N}$ abundance (Mat-251 mass spectrometer, Finnigan, Germany).

Soil samples for root measurements were taken from the microplots with a steel corer of $70 \mathrm{~mm}$ diameter after the shoots harvest. From each microplot, three plants were randomly chosen for soil sampling position. The sampling positions were described in details by Qi et al. ${ }^{[31]}$. Briefly, soil sample north, south and under the plant were collected to $100 \mathrm{~cm}$ soil depth in $20 \mathrm{~cm}$ increments. A 30-35 g soil sample from each section was used for soil $\mathrm{NO}_{3}-\mathrm{N}$ content determination and total $\mathrm{N}$ analysis. The samples were placed in plastic, sealable bags and the bags were placed in refrigerated storage until washing the next day. Roots were washed from soil cores and debris and dead roots were removed from the samples. Samples were then scanned to measure root length. Root length density $\left(\mathrm{cm} / \mathrm{cm}^{3}\right)$ was calculated as the ratio of root length to the volume of the sections for each sampling.

The soil samples were sieved to a $5 \mathrm{~mm}$ mesh size, and then the subsamples used for $\mathrm{NO}_{3}-\mathrm{N}$ content analysis ${ }^{[34]}$. The remaining samples were air-dried, and ground to pass through a $0.15 \mathrm{~mm}$ sieve, and then used for total $\mathrm{N}$ analysis ${ }^{[35]} .{ }^{15} \mathrm{~N}$ abundance analysis in total soil $\mathrm{N}$ was described in details by
Hauck et al. ${ }^{[34]}$

\subsection{Data analysis}

The ${ }^{15} \mathrm{~N}$ enrichment of plants and soil materials is expressed as atom $\%{ }^{15} \mathrm{~N}$ excess. The soil $\mathrm{Ndff} \%$, amount of residual $\mathrm{N}$ fertilizer, plant Ndff\%, plant recovery of ${ }^{15} \mathrm{~N}$, amount of $\mathrm{N}$ fertilizer loss, rate of $\mathrm{N}$ fertilizer residual and loss were calculated by Equations (1)-(7) respectively:

Soil Ndff\% $=$

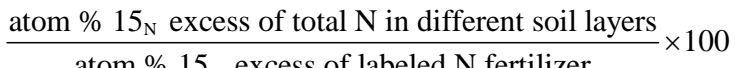

Amount of residual $\mathrm{N}$ fertilizer $=$

Soil total $\mathrm{N}$ in different soil layers $\times$ soil Ndff\%

Plant Ndff\% $\frac{\text { atom } \% 15_{\mathrm{N}} \text { excess of pant } \mathrm{N}}{\text { atom } \% 15_{\mathrm{N}} \text { excess of labeled } \mathrm{N} \text { fertilizer }} \times 100$

Plant recovery of $15_{\mathrm{N}}=\frac{\text { plant }-\mathrm{N} \times \text { plant } \mathrm{Ndff} \%}{\text { amount of labeled } \mathrm{N} \text { fertillzer }} \times 100$

Amount of $\mathrm{N}$ fertilizer loss =

Amount of $\mathrm{N}$ fertilizer application - plant $\mathrm{N} \times$ plant Ndff\% -

Amount of residual $\mathrm{N}$ fertilizer $=$

Rate of $\mathrm{N}$ fertilizer residual $=\frac{\text { Amount of } \mathrm{N} \text { fertilizer residual }}{\text { Amount of labeled N fertilizer }} \times 100$

Rate of $\mathrm{N}$ fertilizer loss $=\frac{\text { Amount of } \mathrm{N} \text { fertilizer loss }}{\text { Amount of labeled } \mathrm{N} \text { fertilizer }} \times 10$

where, plant Ndff\% is the proportion of plant uptake ${ }^{15} \mathrm{~N}$ from the labeled $\mathrm{N}$ fertilizer, soil Ndff\% is the proportion of residual soil ${ }^{15} \mathrm{~N}$ from the labeled $\mathrm{N}$ fertilizer, plant- $\mathrm{N}$ is total $\mathrm{N}$ uptake by aboveground parts of the plant.

The analysis of variance (ANOVA) was performed using one-way ANOVA using SPSS 17.0 software. Treatment means were compared for significant differences $\left(P_{0.05}\right.$ level) using Duncan's multiple range tests.

\section{Results}

\subsection{Grain yield, harvest index and the total $\mathrm{N}$ uptake}

As shown in Table 3, AIANS, AIAND and AICN significantly increased harvest index (ratio of grain yield to shoot biomass) and grain yield compared to CICN. Total $\mathrm{N}$ uptake by maize was significantly greater in AIANS and AICN than that in the other treatments.

Table 3 Grain yield, harvest index (HI) and total nitrogen uptake in maize for different nitrogen supply methods under alternate furrow irrigation and conventional furrow irrigation

\begin{tabular}{cccc}
\hline Treatment & Grain yield $/ \mathrm{kg} \cdot \mathrm{hm}^{-2}$ & $\mathrm{HI} / \%$ & Total N $/ \mathrm{kg} \cdot \mathrm{hm}^{-2}$ \\
\hline AIANS & $10707 \mathrm{a}$ & $53.7 \mathrm{a}$ & $148.8 \mathrm{a}$ \\
AIAND & $9151 \mathrm{~b}$ & $53.4 \mathrm{a}$ & $130.8 \mathrm{~b}$ \\
AICN & $10774 \mathrm{a}$ & $53.7 \mathrm{a}$ & $156.1 \mathrm{a}$ \\
CIAN & $8228 \mathrm{c}$ & $51.4 \mathrm{~b}$ & $119.9 \mathrm{c}$ \\
CICN & $8119 \mathrm{c}$ & $51.3 \mathrm{~b}$ & $123.2 \mathrm{c}$ \\
\hline
\end{tabular}

Note: Values followed by different letters within each column are significantly different at the probability level of 0.05 .

\subsection{Accumulation and distribution of soil $\mathbf{N}$ and $\mathbf{N}$ fertilizer}

The accumulation and distribution proportion of $\mathrm{N}$ in leaves, SS(stem+sheath), BC(bract+cob), and grain of maize derived from the soil were higher than those derived from $\mathrm{N}$ fertilizer (Table 4). The accumulation and distribution proportion of $\mathrm{N}$ were the highest in grain, followed by leaves, SS, and BC in all treatments. The ratio of $\mathrm{N}$ derived from the fertilizer to that from the soil by maize 
was about 4:6. There was no significant difference in the total proportion of $\mathrm{N}$ derived from the soil with different treatments (Table 4). However, grain $\mathrm{N}$ uptake from $\mathrm{N}$ fertilizer and its distribution proportion were significantly higher in AIAN, AIANS and AIANS plants than those in CICN and CIAN plants. On the contrary, the proportion of $\mathrm{N}$ fertilizer uptake by leaves to total $\mathrm{N}$ uptake was significantly lower in the AI plants than that in the CI plants (Table 4). The accumulation of $\mathrm{N}$ in leaves, SS, BC and grain of maize derived from soil were all significantly greater in AIANS and AICN than those in CICN, CIAN and AIAND (Table 4). The total $\mathrm{N}$ fertilizer uptake by maize was significantly greater in the AI plants than in the CI plants.

Table 4 Accumulation and distribution of nitrogen in different organs of maize from different sources at maturity for different nitrogen supply methods under alternate furrow irrigation and conventional furrow irrigation

\begin{tabular}{|c|c|c|c|c|c|c|c|c|c|c|c|}
\hline \multirow{2}{*}{$\begin{array}{l}\text { Nitrogen } \\
\text { source }\end{array}$} & \multirow{2}{*}{ Treatment } & \multicolumn{5}{|c|}{$\mathrm{N}$ accumulation amount $/ \mathrm{kg} \cdot \mathrm{hm}^{-2}$} & \multicolumn{5}{|c|}{ Distribution proportion/\% } \\
\hline & & Leaf & SS & BC & Grain & Total & Leaf & SS & $\mathrm{BC}$ & Grain & Total \\
\hline \multirow{4}{*}{ NDFF } & AIANS & 9.26 & 6.81 & 3.32 & $36.89 a$ & $56.28 a$ & $6.22 b$ & 4.58 & 2.23 & $24.79 a$ & 37.82 \\
\hline & AICN & 7.96 & 7.19 & 3.48 & 39.38a & $58.02 \mathrm{a}$ & $5.10 \mathrm{~b}$ & 4.61 & 2.23 & $25.23 a$ & 37.17 \\
\hline & CIAN & 11.91 & 5.28 & 2.71 & $27.66 \mathrm{c}$ & $47.56 \mathrm{~b}$ & $9.43 a$ & 4.90 & 2.26 & $23.07 b$ & 39.67 \\
\hline & CICN & 10.63 & 5.18 & 2.66 & $28.89 \mathrm{c}$ & $45.86 \mathrm{~b}$ & 8.63a & 4.21 & 2.16 & $23.45 b$ & 37.22 \\
\hline \multirow{5}{*}{ NDFS } & AIANS & $19.52 a$ & $11.19 a$ & $5.46 a$ & $56.34 a$ & $92.52 a$ & 13.12 & 7.52 & 3.67 & 37.87 & 62.18 \\
\hline & AIAND & $16.93 \mathrm{~b}$ & $9.16 b$ & $4.43 \mathrm{~b}$ & $47.14 \mathrm{~b}$ & $77.66 \mathrm{~b}$ & 12.94 & 7.01 & 3.38 & 36.04 & 59.37 \\
\hline & AICN & $21.28 \mathrm{a}$ & $12.16 \mathrm{a}$ & $5.88 \mathrm{a}$ & $58.75 a$ & $98.08 \mathrm{a}$ & 13.63 & 7.79 & 3.77 & 37.64 & 62.83 \\
\hline & CIAN & $15.48 \mathrm{~b}$ & $8.03 \mathrm{~b}$ & $4.12 b$ & $44.71 \mathrm{~b}$ & $72.34 \mathrm{~b}$ & 12.91 & 6.70 & 3.44 & 37.29 & 60.33 \\
\hline & CICN & $16.47 \mathrm{~b}$ & $8.74 b$ & $4.49 \mathrm{~b}$ & $47.64 \mathrm{~b}$ & 77.34b & 13.37 & 7.09 & 3.64 & 38.67 & 62.78 \\
\hline
\end{tabular}

Note: NDFF-N derived from fertilizer; NDFS-N derived from soil; BC-maize bract+Cob; SS-Stem+Sheath; Values followed by different letters within each column and nitrogen source are significantly different at the probability level of 0.05 .

\subsection{Atom $\%$ of ${ }^{15} \mathrm{~N}$ excess in different soil layers after maize harvest}

ANOVA analysis showed that there was no significant difference in the atom $\%$ of ${ }^{15} \mathrm{~N}$ excess among different sampling positions (north, south and under the plant) of each soil layer in all treatments. Therefore, atom $\%$ of ${ }^{15} \mathrm{~N}$ excess in the different positions within a same soil layer was pooled. Atom \% of ${ }^{15} \mathrm{~N}$ excess in all treatments decreased with the increase in soil layers (Figure 1). The peak in atom $\%$ of ${ }^{15} \mathrm{~N}$ excess was found in the $20-40 \mathrm{~cm}$ soil layer (Figure 1). The atom $\%$ of ${ }^{15} \mathrm{~N}$ excess in the 0-60 cm soil layers was highest in AIAND, intermediate in AIANS and AICN, and lowest in CICN and CIAN $(p<0.05)$. However, CI plants had a higher atom $\%$ of ${ }^{15} \mathrm{~N}$ excess in $60-100 \mathrm{~cm}$ soil layers compared with AI plants $(p<0.05)$.

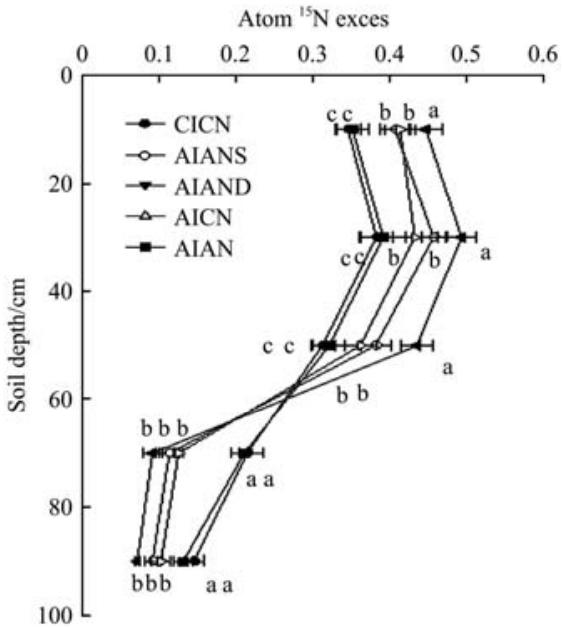

Note: AI, alternate furrow irrigation; CI, conventional furrow irrigation; AN, alternate nitrogen supply; $\mathrm{CN}$, conventional nitrogen supply; AIANS and AIAND represent synchronized and separation supply of nitrogen fertilizer and water under AI respectively; the same below. Values (mean \pm standard error, $n=3$ ) in each soil depth were averaged across different positions (north, south and under the plant).

Figure 1 Distribution of atom \% 15N excess of total nitrogen in the $0-100 \mathrm{~cm}$ soil layer after maize harvest for different nitrogen supply methods under alternate furrow irrigation and conventional furrow irrigation

\subsection{Residual $\mathrm{NO}_{3}-\mathrm{N}$ in $\mathbf{0 - 1 0 0} \mathrm{cm}$ soil layers}

As shown in Figure 2, the amount of soil residual $\mathrm{NO}_{3}-\mathrm{N}$ decreased with the soil layer deepening in all treatments. The residual $\mathrm{NO}_{3}-\mathrm{N}$ in the $0-40 \mathrm{~cm}$ soil layers was significantly smaller in AIANS, AIAND and AICN than those in CICN and CIAN. The residual $\mathrm{NO}_{3}-\mathrm{N}$ in $60-100 \mathrm{~cm}$ soil layers was the greatest in CICN and CIAN, intermediate in AIANS and AICN, and smallest in AIAND. The residual $\mathrm{NO}_{3}-\mathrm{N}$ in the $0-100 \mathrm{~cm}$ soil layers was significantly greater in the CI plants than in the AI plants.

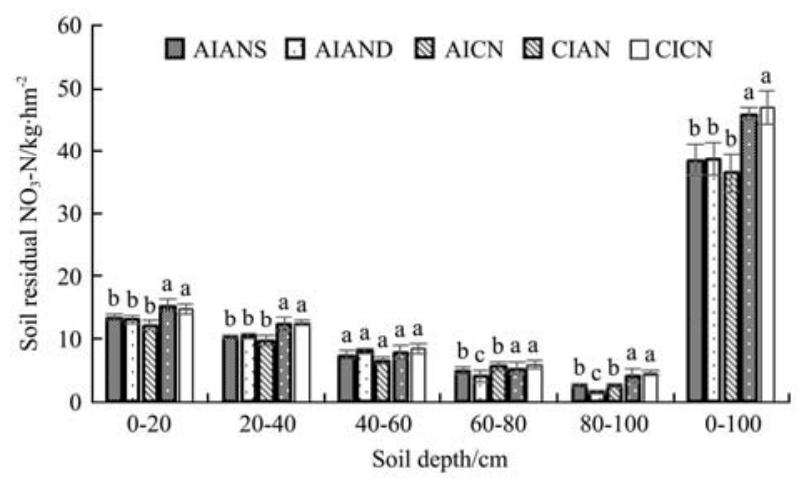

Note: Values (means \pm standard error, $n=3$ ) followed by different letters within each soil depth are significantly different at the probability level of 0.05 .

Figure 2 Residual $\mathrm{NO}_{3}-\mathrm{N}$ in the $0-100 \mathrm{~cm}$ soil layer after maize harvest as affected by different nitrogen supply methods under alternate furrow irrigation and conventional furrow irrigation

\subsection{Fate of labeled $\mathbf{N}$ fertilizer}

As shown in Table 5 , the ${ }^{15} \mathrm{~N}$ uptake by crop was greater than the ${ }^{15} \mathrm{~N}$ loss for AIANS, AIDND and AICN although the difference was not statistically significant $(p>0.05)$. However, the ${ }^{15} \mathrm{~N}$ uptake was significantly smaller than the ${ }^{15} \mathrm{~N}$ loss for CICN and CIAN $(p<0.05) .{ }^{15} \mathrm{~N}$ uptake by crop was significantly greater in AIANS, AIAND and AICN than in those in CICN and CIAN. The ${ }^{15} \mathrm{~N}$ loss showed an opposite observation. The residual ${ }^{15} \mathrm{~N}$ in 0-100 $\mathrm{cm}$ soil layers was the greatest in AIAND treatment, intermediate in AIANS and AICN, and smallest in CICN and CIAN. The rates of ${ }^{15} \mathrm{~N}$ uptake, residual and loss were consistent with the amount of those among the different treatments. These indicated that alternate furrow irrigation could help increase ${ }^{15} \mathrm{~N}$ 
uptake by maize while reduce ${ }^{15} \mathrm{~N}$ loss.

\begin{tabular}{|c|c|c|c|c|c|c|}
\hline \multirow{2}{*}{ Treatment } & \multicolumn{2}{|c|}{ Crop ${ }^{15} \mathrm{~N}$ uptake } & \multicolumn{2}{|c|}{$\begin{array}{l}\text { Residual }{ }^{15} \mathrm{~N} \text { in the } \\
0-100 \mathrm{~cm} \text { soil layer }\end{array}$} & \multicolumn{2}{|c|}{${ }^{15} \mathrm{~N}$ loss } \\
\hline & $\mathrm{kg} \cdot \mathrm{hm}^{-2}$ & $\%$ & $\mathrm{~kg} \cdot \mathrm{hm}^{-2}$ & $\%$ & $\mathrm{~kg} \cdot \mathrm{hm}^{-2}$ & $\%$ \\
\hline AIANS & 56.28a & 28.14a & 88.91b & $44.46 \mathrm{~b}$ & $54.81 \mathrm{~b}$ & $27.41 \mathrm{~b}$ \\
\hline AIAND & 53.14a & 26.57a & 95.31a & $47.66 a$ & 51.55b & $25.78 b$ \\
\hline AICN & $58.02 \mathrm{a}$ & 29.01a & 89.34b & $44.67 \mathrm{~b}$ & $52.64 \mathrm{~b}$ & $26.32 b$ \\
\hline CIAN & $47.56 \mathrm{~b}$ & $23.78 \mathrm{~b}$ & 83.70c & $41.85 \mathrm{c}$ & 68.74a & $34.37 \mathrm{a}$ \\
\hline CICN & 45.86b & 22.93b & $84.38 \mathrm{c}$ & $42.19 \mathrm{c}$ & 69.76a & $34.88 \mathrm{a}$ \\
\hline
\end{tabular}

Note: Values followed by different letters within each column are significantly different at the probability level of 0.05 .

\subsection{Root vertical distribution}

ANOVA analysis showed that the difference in root length density (RLD) between two $\mathrm{N}$ supply methods of each soil layer was not statistically significant under AI and CI. Thus, the RLD at the two $\mathrm{N}$ supply methods in each irrigation treatment was pooled. The RLD decreased consistently with the soil layer deepening. The RLD in each soil layer was greater in the AI plants than that in the CI plants, and the difference was statistically significant in the $0-40 \mathrm{~cm}$ soil layers (Figure 3).

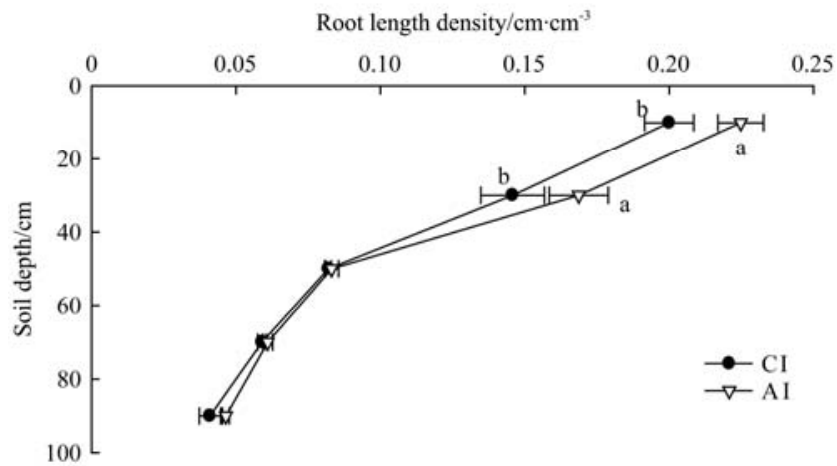

Note: Values (mean \pm standard error, $n=3$ ) followed by different letters within each soil layer are significantly different at the probability level of 0.05. Data in each soil layer was averaged across different nitrogen supply methods (conventional and alternate nitrogen supply method) and different sampling positions (north, south and under the plant).

Figure 3 Distribution of root length density in the $0-100 \mathrm{~cm}$ soil layer after maize harvest for alternate furrow irrigation (AI) and conventional furrow irrigation (CI)

\section{Discussion}

In the present study, AIANS and AICN significantly improved the total $\mathrm{N}$ uptake by maize compared to AIAND and CICN (Table 3). The reduced $\mathrm{N}$ accumulation in AIAND could be related to the lower $\mathrm{N}$ uptake from the relatively dry soil zones. In AIAND, the separation of fertilizer $\mathrm{N}$ from the irrigated furrow each time resulted in that the root zone of $\mathrm{N}$ supplied became relatively dry. In CICN, CI resulted in the decreased soil water content in the plough layer (0-40 cm soil layers) compared to $\mathrm{AI}^{[22]}$. It has been shown that the soil $\mathrm{N}$ availability and its transport to the roots are determined by soil moisture content ${ }^{[7]}$. Both mass flow and diffusion rates and the release rate of the nutrient of available $\mathrm{N}$ were reduced by water deficit ${ }^{[24]}$, resulting in the decreased $\mathrm{N}$ uptake under AIAND and CICN (Table 3). Moreover, in this study, biomass was smaller in AIAND, which contributed to the reduced total $\mathrm{N}$ uptake ${ }^{[36]}$. Thus, these results suggested that the synchronized supply of $\mathrm{N}$ fertilizer and water with alternate furrow irrigation was useful to improve $\mathrm{N}$ accumulation in maize. In addition, Han et al. ${ }^{[11]}$ found that AIAND could significantly improve $\mathrm{N}$ accumulation in summer maize compared to conventional irrigation and fertilization. Consistently, herein we observed that the total $\mathrm{N}$ uptake by maize was greater in AIAND than that in CICN (Table 3). Although with different weather conditions, such as the average precipitation per year in this study (164 mm) was only approximately $20 \%$ of that in Han et al. (2014)'s study.

Both atom \% of ${ }^{15} \mathrm{~N}$ excess and residual $\mathrm{NO}_{3}-\mathrm{N}$ in the 60-100 cm soil layers were significantly lower in AIANS, ANAND and AICN compared to those in CICN (Figures 1 and 2). This could be explained as following: root growth status and soil $\mathrm{N}$ availability are the two important factors responsible for determining $\mathrm{N}$ use efficiency ${ }^{[6]}$. An earlier study illustrated that AI enhances rooting depth, contributing to the improvement of $\mathrm{N}$ uptake in field grown plants from deeper soil layers ${ }^{[36]}$. Correspondingly, the RLD in $60-100 \mathrm{~cm}$ soil layers was higher in the AI plants than in the CI plants although the differences were not statistically significant (Figure 3), resulting in the enhanced $\mathrm{N}$ uptake from 60-100 cm soil layers. Moreover, AI plants significantly enhanced $\mathrm{N}$ uptake from the sources of $\mathrm{N}$ fertilizer and soil (Table 4). This was associated with the enhanced RLD under AI (Figure 2). Since a higher RLD usually have a greater root surface area ${ }^{[31,37]}$, resulting in the improved $\mathrm{N}$ accumulation of the plants.

Using ${ }^{15} \mathrm{~N}$-labeled technology, Wang et al. ${ }^{[6]}$ found that AI significantly increase $\mathrm{N}$ contents in the leaves, stems and tubers, whereas the ${ }^{15} \mathrm{~N}$ content in the reproductive organ are comparable between $\mathrm{AI}$ and $\mathrm{CI}$. In line with this, AI increased $\mathrm{N}$ uptake in maize plants (Table 3); whereas AIANS, AIAND and AICN significantly increased ${ }^{15} \mathrm{~N}$ accumulation in the grain compared to CICN and CIAN (Table 4). This could be explained as following: AI could reduce redundant plant growth and optimize the distribution of carbohydrates among the different organs ${ }^{[36]}$, which indicated by AI plants resulted in a greater harvest index to CI plants (Table 3). Thus, we speculate that AI enhanced the transfer of the ${ }^{15} \mathrm{~N}$ from the leaves to the grain. Correspondingly, irrigation treatments were only continued for about four weeks under a pot culture in Wang et al.'s study ${ }^{[6]}$ A relatively shorter experimental time may not be enough for the transfer of the absorbed ${ }^{15} \mathrm{~N}$ by plants from the nutritive organ to reproductive organ.

An earlier study has shown that AI promotes the upward movement of ${ }^{15} \mathrm{~N}$ from the $60-100 \mathrm{~cm}$ to $0-40 \mathrm{~cm}$ soil layers as compared with $\mathrm{CI}^{[38]}$. In agreement with this, atom percentage ${ }^{15} \mathrm{~N}$ excess in the $0-60 \mathrm{~cm}$ soil layers was greater in the AI plants than those in the CI plants, and it was greatest in AIAND (Figure 1). This was associated with varying dynamics of soil water under different irrigation methods. In CI, the vertical movement is a major form in soil water, resulting in the increased probability of the deep percolation. However, the alternate drying/wetting cycles enhances the lateral movement of the water in soil under AI, thereby reducing the deep percolation ${ }^{[39]}$. Moreover, the separation of $\mathrm{N}$ fertilizer application from irrigated furrow with $\mathrm{AI}$ was favor to maintain a high soil $\mathrm{N}$ availability in the $0-40 \mathrm{~cm}$ soil layers for a longer period of time ${ }^{[40]}$. In addition, the greatest residual percentage of ${ }^{15} \mathrm{~N}$ in the $0-100 \mathrm{~cm}$ soil layers was found in AIAND (Table 5). The residual ${ }^{15} \mathrm{~N}$ usually does not disappear immediately, which play a vital role in recharging soil $\mathrm{N}$ pool ${ }^{[14]}$.

In the present study, crop ${ }^{15} \mathrm{~N}$ uptake rate was significantly 
higher in the AI plants than that in the CI plants (Table 5). This confirms our earlier findings that AI resulted in a higher recovery rate of $\mathrm{N}^{15}$ fertilizer, which derived from a pot culture ${ }^{[7]}$. Moreover, Zhang et al. ${ }^{[41]}$ suggested that root ${ }^{15} \mathrm{~N}$ uptake is positively correlated with RLD in wheat plants. In consistent with this, the correlation analysis showed that ${ }^{15} \mathrm{~N}$ uptake by maize was positively correlated with RLD in the $0-40 \mathrm{~cm}$ soil layers at the $\mathrm{R}_{6}$ stage of maize $(r=0.836, p<0.01)$. Since plant roots systems are involved in acquisition of nutrients and water ${ }^{[42,43]}$. In addition, it has been shown that water utilization and nutrients uptake by crop is a function of temporal and spatial distribution of the roots systems $^{[44]}$. Thus, we suggested that enhanced root length density contributes to the increased ${ }^{15} \mathrm{~N}$ uptake rate under alternate furrow irrigation.

Earlier studies suggested that localized supply of $\mathrm{N}$ fertilizer can meet the $\mathrm{N}$ requirements of plants as conventional supply of $\mathrm{it}^{[12,45]}$. In agreement with this, all the measured parameters were comparable between AIANS and AICN. Because of the compensatory effect, roots $\mathrm{N}$ uptake capacity of $\mathrm{N}$ supplied zone is significantly enhanced to compensate for the lack of $\mathrm{N}$ fertilizer in zero-N supplied zone ${ }^{[46]}$. Moreover, the distribution of soil $\mathrm{NO}_{3}-\mathrm{N}$ and water dynamics in the $0-100 \mathrm{~cm}$ soil layers were comparable between AIANS and AICN during the crop grown season $^{[30]}$. Nevertheless, the application of $\mathrm{N}$ fertilizer to the half furrows in AIANS are labor-saving than the all furrows in AICN. Thus, the synchronized supply of water and $\mathrm{N}$ fertilizer with alternate furrow irrigation can be better practiced in maize production.

\section{Conclusions}

With a same amount of nitrogen fertilizer and irrigation water, compared to conventional furrow irrigation coupled with conventional nitrogen supply, alternate furrow irrigation together with either conventional or alternate nitrogen supply generated a greater grain yield, root length density, harvest index, nitrogen accumulation in maize, atom $\%$ of ${ }^{15} \mathrm{~N}$ excess in the $0-60 \mathrm{~cm}$ soil layer, ${ }^{15} \mathrm{~N}$ accumulation in grain, residual ${ }^{15} \mathrm{~N}$ and ${ }^{15} \mathrm{~N}$ uptake rates, and lower the residual soil $\mathrm{NO}_{3}-\mathrm{N}$ in the $0-100 \mathrm{~cm}$ soil layers and ${ }^{15} \mathrm{~N}$ loss rate. Moreover, the synchronized supply of nitrogen fertilizer and water was superior to the separation of them in improving the most those parameters under alternate furrow irrigation. The enhanced root length density contributed to the improved ${ }^{15} \mathrm{~N}$ uptake rate under alternate furrow irrigation. Therefore, ${ }^{15} \mathrm{~N}$ uptake rate by maize was improved while the ${ }^{15} \mathrm{~N}$ loss rate was reduced under alternate furrow irrigation when conventional or alternate nitrogen (synchronized supply of nitrogen and water) application methods was used.

\section{Acknowledgements}

We acknowledge that the research was financially supported by the National Natural Science Fund of China (Grant No. 51809006; 51079124).

\section{[References]}

[1] Morison J I. L, Baker N R, Mullineaux P M, Davies W J. Improving water use in crop production. Philosophical Transactions of the Royal Society, 2008; 363: 639-658.

[2] English M J, Raja S J. Perspectives on deficit irrigation. Agricultural Water Management, 1996; 32: 1-14.

[3] Kang S Z, Liang Z S, Pan Y H, Shi P Z, Zhang J H. Alternate furrow irrigation for maize production in arid area. Agricultural Water
Management, 2000; 45: 267-274.

[4] Loveys B R, Stoll M, Dry P, McCarthy M. Using plant physiology to improve the water use efficiency of horticultural crops. Acta Horticulture, 2000; 537: 187-197.

[5] Dodd I C. Rhizposphere manipulations to maximize 'cropper drop' during deficit irrigation. Journal of Experimental Botany, 2009; 60: 1-6.

[6] Wang H Q, Liu F L, Andersen M N, Jensen C R. Comparative effects of partial root-zone drying and deficit irrigation on nitrogen uptake in potatoes (Solanum tuberosum L.). Irrigation Science, 2009; 27: 443-448.

[7] Hu T T, Kang S Z, Li F S, Zhang J H. Effects of partial root-zone irrigation on the nitrogen absorption and utilization of maize. Agricultural Water Management, 2009; 96: 208-214

[8] Wang Y S, Liu F L, Andersen M N, Jensen C R. Improved plant nitrogen nutrition contributes to higher water use efficiency in tomatoes under alternate partial root-zone irrigation. Functional Plant Biology, 2010; 37: 175-182.

[9] Wang Y S, Liu F L, deNeergaard A, Jensen L S, Luxhøi J, Jensen C R. Alternate partial root-zone irrigation induced dry/wet cycles of soils stimulate $\mathrm{N}$ mineralization and improve $\mathrm{N}$ nutrition in tomatoes. Plant and Soil, 2010; 337: 167-177.

[10] Ju X T, Xing G X, Chen X P, Zhang S L, Zhang L J, Liu X J, et al. Reducing environmental risk by improving $\mathrm{N}$ management in intensive Chinese agricultural systems. Proceedings of the National Academy of Sciences of the United States of America, 2009; 106: 3041-3046.

[11] Han K, Yang Y, Zhou C J, Shangguan Y X, Zhang L, Li N, et al. Management of furrow irrigation and nitrogen application on summer maize. Agronomy Journal, 2014; 106(4): 1402-1410.

[12] Skinner R H, Han J, Benjamin J. Nitrogen uptake and portioning under alternate and every-furrow irrigation. Plant and Soil, 1999; 210: 11-20.

[13] Benjamin J G, Porter L K, Duke H R, Ahuja L R. Corn growth and nitrogen uptake with furrow irrigation and fertilizer bands. Agronomy Journal, 1997; 89: 609-612.

[14] Ju X T, Liu X J, Pan J R, Zhang F S. Fate of ${ }^{15} \mathrm{~N}$-labled urea under a winter wheat-summer maize rotation on the North China plain. Pedosphere, 2007; 17: 52-61.

[15] Kirda C, Topcu S, Kaman H, Ulger A C, Yazici A, Cetin M, et al. Grain yield response and $\mathrm{N}$-fertilizer recovery of maize under deficit irrigation. Field Crops Research, 2005; 93:132-141.

[16] Wang Z C, Liu F L, Kang S Z, Jensen C R. Alternate partial root-zone drying irrigation improves nitrogen nutrition in maize (Zea mays L.) leaves. Environmental Experimental Botany, 2012; 75: 36-40.

[17] Li Z J, Zhang F C, Kang S Z. Impacts of the controlled roots divided alternative irrigation on water and nutrient use of winter wheat. Transactions of the CSAE, 2005; 21(8): 17-21. (in Chinese).

[18] Wang Y S, Liu F L, Jensen L S, Neergaard A, Jensen C R. Alternate partial root-zone irrigation improves fertilizer- $\mathrm{N}$ use efficiency in tomatoes. Irrigation Science, 2013; 31: 589-598.

[19] Wang Y S, Janz B, Engedal T, de Neergaard A. Effect of irrigation regimes and nitrogen rates on water use efficiency and nitrogen uptake in maize. Agricultural Water Management, 2017; 179: 271-276.

[20] Kang S Z, Su X L, Tong L, Shi P Z, Yang X Y, Abe Y K, et al. The impacts of human activities on the water-land environment of the Shiyang River basin, an arid region in northwest China. Hydrological Science of Journal, 2004; 49: 413-427.

[21] Du T S, Kang S Z, Zhang J H, Davis W. Deficit irrigation and sustainable water-resource strategies in agriculture for China's food security. Journal of Experimental Botany, 2015; 66: 2253-2269.

[22] Qi D L, Hu T T, Liu T T. Biomass accumulation and distribution, yield formation and water use efficiency responses of maize (Zea mays L.) to nitrogen supply methods under partial root-zone irrigation. Agricultural Water Management, 2020; 230: 105981.

[23] Hodge C A, Neculai N P. Pollution control in fertilizer production. New York: CRC Press, 1994; pp.35-81.

[24] Li S X, Wang Z H, Malhi S, Li S Q, Gao Y J, Tian X H. Nutrient and water management effects on crop production, and nutrient and water use efficiency in dryland areas of China. Advances in Agronomy, 2009; 102: 223-265.

[25] Fageria N K, Baligar V C. Enhancing nitrogen use efficiency in crop plants. Advances in Agronomy, 2005; 88: 97-185.

[26] Miyatake M, Ohyama T, Yokoyama T, Sugihara S, Motobayashi T, Takehiro K, et al. Effects of deep placement of controlled-release nitrogen fertilizer on soybean growth and yield under sulfur deficiency. Soil Science and Plant Nutrition, 2019; 65(3): 255-269. 
[27] Zhang L J, Ju X T, Gao Q, Zhang F S. Recovery of ${ }^{15} \mathrm{~N}$-labeled nitrate injected into deep subsoil by maize in a calcareous alluvial soil on the North China Plain. Communication in Soil Science and Plant Analysis, 2007; 38: 1563-1577.

[28] Mao Z, Cui, Y L, Dong B. Rice irrigation technique for efficient water saving and sustainable getting high yield. Water Resources and Hydropower Engineering, 2002; 33: 65-67. (in Chinese).

[29] Skinner R H, Hanson J D, Benjamin G H. Roots distribution following separation of water and nitrogen supply in furrow irrigated corn. Plant and Soil, 1998; 199: 187-194.

[30] Qi D L, Hu T T. Effects of varied nitrogen supply and irrigation methods on distribution and dynamics of soil $\mathrm{NO}_{3}-\mathrm{N}$ during maize season. Journal of Agricultural Science, 2017; 9: 1-14.

[31] Qi D L, Hu T T, Niu X L. Responses of root growth and distribution of maize to nitrogen application patterns under partial root-zone irrigation. International Journal of Plant Production, 2017; 11: 209-224.

[32] Yang R, Su Y Z. Effects of nitrogen fertilization and irrigation rate on grain yield, nitrate accumulation and nitrogen balance on sandy farmland in the marginal oasis in the middle of Heihe River basin. Acta Ecology Sinica, 2009; 28: 1460-1469. (in Chinese).

[33] Yang X Y, Du T S, Pan Y H, Zhang H R. Scheduling irrigation for maize under different irrigation methods in Minqin oasis. Journal of Irrigation and Drainage, 2003; 22: 22-24. (in Chinese).

[34] Hauck R D, Meisinger J J, Mulvaney R L. Practical considerations in the use of nitrogen tracers in agricultural and environmental research. In Weaver R W, Angle J S and Bottomley P S (eds.), Methods of soil analysis. Part 2: Microbiological and biochemical properties. SSSA Book Series: No.5. SSSA and ASA, Madison, WI, 1996; pp.907-950.

[35] Bremner M. Nitrogen-total. In Sparks D L (ed.), Methods of soil analysis. Part 3: Chemical methods. SSSA Book Series: No.5. SSSA and ASA, Madison, WI, 1996; pp.1085-1121.

[36] Kang S Z, Zhang J H. Controlled alternate partial root-zone irrigation: its physiological consequences and impact on water use efficiency. Journal of Experimental Botany, 2004; 407: 2437-2446.

[37] Mingo D M, Theobald J C, Bacon M A, Davies W J, Dodd I C. Biomass allocation in tomato (Lycopersiconesculentum) plants grown under partial rootzone drying: enhancement of root growth. Functional Plant Biology, 2004; 31: 971-978.

[38] Wang C H, Zhu P F, Shu L Z, Zhu J R, Yu H M, Zhan Y S, et al. Effects of alternate partial root-zone irrigation and nitrogen forms on utilization and movement of nitrate in soil. Transactions of the CSAE, 2014; 30(11): 92-101. (in Chinese).

[39] Zhou Q Y, Kang S Z, Li F S, Zhang L. Comparison of dynamic and static APRI-models to simulate soil water dynamics in a vineyard over the growing season under alternate partial root-zone drip irrigation. Agricultural Water Management, 2008; 95: 767-775.

[40] Xing W Q, Wang L Q, Li L P, Li S X. Effect of water -fertilized spatial coupling on corn in semiarid area II dynamics distribution of water and available nitrogen in soil. Soil, 2003; 35(3): 242-247. (in Chinese).

[41] Zhang L J, Ju X T, Gao Q, Zhang F S. Recovery of labeled nitrate-N in different soil layers by two kinds of crops. Scientia Agricultura Sinica, 2005; 38: 333-340

[42] Aziz O, Hussain S, Rizwan M, Riaz M, Bashir S, Lin L, et al. Increasing water productivity, nitrogen economy, and grain yield of rice by water saving irrigation and fertilizer-N management. Environmental Science and Pollution Research, 2018; 25(17): 16601-16615.

[43] Qi D L, Hu T T, Song X. Effect of nitrogen supply method on root growth and grain yield of maize under alternate partial root-zone irrigation. Scientific Reports, 2019; 9: 81-91.

[44] Wang C Y, Liu W X, Li Q X, Ma D Y, Lu H F, Feng W, et al. Effects of different irrigation and nitrogen regimes on root growth and its correlation with above-ground plant parts in high-yielding wheat under field conditions. Field Crops Research, 2014; 165: 138-149.

[45] Dong J, Jones R H, Mou P. Relationships between nutrient heterogeneity, root growth, and hormones: Evidence for interspecific variation. Plants, 2018; 7: 2-16.

[46] Zhang H, Jennings A J, Barlow P W, Forde B G. Dual pathways for regulation of root branching by nitrate. Proceedings of the National Academy of Sciences of the United States of America, 1999; 96: 6529-6534. 